\title{
Endoscopic Yield, Appropriateness, and Complications of Pediatric Upper Gastrointestinal Endoscopy in an Adult Suite: A Retrospective Study of 822 Children
}

\author{
Manzoor Ahmad Wani ${ }^{1}$, Showkat Ali Zargar ${ }^{2}$, Ghulam Nabi Yatoo ${ }^{2}$, Inaamul $\mathrm{Haq}^{3}$, Altaf Shah' ${ }^{2}$, Jaswinder Singh Sodhi', \\ Ghulam Mohammad Gulzar ${ }^{2}$ and Mushtaq Khan ${ }^{2}$ \\ ${ }^{1}$ Department of Gastroenterology and Hepatology, Jawahar Lal Nehru Memorial Hospital (JLNMH), Srinagar, ${ }^{2}$ Department of \\ Gastroenterology and Hepatology, Sher-i-Kashmir Institute of Medical Sciences (SKIMS), Srinagar, ${ }^{3}$ Department of Community Medicine, \\ Government Medical College (GMC) Srinagar, Srinagar, India
}

Background/Aims: This study aimed to study the endoscopic yield, appropriateness, and complications of pediatric endoscopy performed by adult gastroenterologists in an adult endoscopic suite.

Methods: This a retrospective study in which records of all the patients less than 18 years of age who underwent endoscopy in the last 5 years were studied. The indications of endoscopy in children were categorized as appropriate or inappropriate per the latest guidelines by American Society for Gastrointestinal Endoscopy and North American Society for Pediatric Gastroenterology, Hepatology and Nutrition. Positive endoscopic yield was defined as the presence of any abnormality on endoscopy.

Results: Among the total of 822 children (age < 18 years), the most common indications were variceal surveillance/eradication in 157 (19.1\%), followed by dyspepsia in 143 (17.4\%), upper gastrointestinal (UGI) bleeding in 136 (16.5\%), recurrent abdominal pain in 94 (11.4\%), unexplained anemia in 74 (9\%), recurrent vomiting in 50 (6.08\%), chronic refractory gastroesophageal reflux disease in 34 (4.1\%) and others; 780 out of 822 endoscopic procedures (94.9\%) done in children were appropriate as per the guidelines. The endoscopic yield was $45.8 \%$, highest in patients with UGI bleeding (71.3\%), followed by variceal surveillance (54.8\%), recurrent vomiting (38\%), dyspepsia (37.8\%), and recurrent abdominal pain (36\%). Minor adverse events occurred in $7.3 \%$ of children.

Conclusions: Pediatric endoscopy performed by an experienced adult gastroenterologist may be acceptable if done in cooperation with a pediatrician. Clin Endosc 2020;53:436-442

Key Words: Child; Complications; Endoscopy

\section{INTRODUCTION}

Upper gastrointestinal (UGI) diseases are common in children worldwide, and digestive endoscopy can be a very

Received: June 19, 2019 Revised: September 22, 2019

Accepted: October 17, 2019

Correspondence: Manzoor Ahmad Wani

Department of Gastroenterology and Hepatology, Jawahar Lal Nehru Memorial Hospital (JLNMH), Rainawari, Srinagar, Jammu and Kashmir 190003, India Tel: +91-990-693-6887, Fax: +91-01942507099, E-mail: drmanzoorahmadwani@ gmail.com

ORCID: https://orcid.org/0000-0002-5940-4494

(c) This is an Open Access article distributed under the terms of the Creative Commons Attribution Non-Commercial License (http://creativecommons.org/ licenses/by-nc/3.0) which permits unrestricted non-commercial use, distribution, and reproduction in any medium, provided the original work is properly cited. helpful diagnostic and therapeutic tool for them. In 1972, Freeman, a British pediatric surgeon, reported using the fiber-optic bronchoscope for examination of the UGI tract in children; since then, gastrointestinal endoscopy in children has developed at a rapid pace. ${ }^{1,2}$ Initially, pediatric endoscopy was mainly used for the identification of superficial lesions, which were not seen on radiographic contrast studies, and for diagnosing specific causes of UGI bleeding. ${ }^{2,3}$ Esophagogastroduodenoscopy (EGD) can now be done at any age because of the development of flexible endoscopes with a small caliber and proper training of operators. Diagnostic pediatric EGD is usually safe, ${ }^{4}$ and complications are rarely encountered. Complications mostly occur due to sedation and anesthesia administered during the procedure. ${ }^{5}$ However, therapeutic 
endoscopy in children can have multiple complications depending upon the nature of intervention and expertise of the endoscopist, with the reported complication rate of less than $1 \%$ when EGD is done by expert pediatric endoscopists. ${ }^{4}$

The indications of UGI endoscopy in children are almost similar to those in adults, ${ }^{6}$ but sometimes endoscopy in children is also done when they present with unexplained signs and symptoms like irritability, anorexia, and failure to thrive. ${ }^{7}$ The American Society for Gastrointestinal Endoscopy (ASGE) and the North American Society for Pediatric Gastroenterology, Hepatology and Nutrition (NASPGHAN) have published modifications to endoscopic practice for the pediatric population in 2014 where they have mentioned appropriate indications for EGD in children. ${ }^{8}$

The endoscopic yield in children is almost similar to that in adults and varies from $35 \%$ to $45 \%$ in the literature. Since the success of endoscopy in children requires adequate knowledge and understanding of a child's medical background, pediatric endoscopy is mainly done by pediatric gastroenterologists and, occasionally, by pediatric surgeons trained in endoscopy. ${ }^{7}$ However, in the absence of properly-trained pediatric gastroenterologists, adult endoscopists under the supervision of a pediatrician can provide basic and advanced therapeutic endoscopic services as acknowledged by NASPGHAN. ${ }^{8,9}$ There are only a few studies on the endoscopic yield and appropriateness of pediatric endoscopy, ${ }^{10-15}$ and studies that have evaluated these aspects in an adult endoscopic suite are very scarce. Also, only a relatively small number of studies have been done in an adult endoscopic suite and these studies had only a small number of patients. ${ }^{16,17}$ Besides, the appropriateness of pediatric endoscopy in an adult suite has never been studied.

Our center does not have a pediatric gastroenterology unit, thus, all the pediatric endoscopic procedures referred to us are done by adult gastroenterologists in an adult endoscopic suite. We believe that a similar scenario is experienced by many centers around the world where a large number of pediatric endoscopic procedures are done by the adult gastroenterologists. Hence, this retrospective study was carried out with the aim of analyzing the appropriateness, endoscopic yield, and complications of pediatric endoscopic procedures done by adult gastroenterologists in an adult suite.

\section{MATERIALS AND METHODS}

This is a single-center retrospective study carried out in the Department of Gastroenterology at the sole tertiary care hospital of the valley of Kashmir over the last 5 years. Patients were identified from the Institute's Medical Records Department and the Departmental database of endoscopy patients.
All children less than 18 years of age who underwent endoscopy in our endoscopic unit were included in the study. Neonates and patients with incomplete data regarding the indications, endoscopic findings, and complications were excluded. Demographic data, preliminary diagnosis, indications for endoscopy, sedation/anesthesia, endoscopic findings, adverse events, and final diagnosis were recorded and analyzed. The majority of the endoscopic procedures were done with adult video endoscopes (OLYMPUS GIF-Q150 and GIF-Q190; Olympus, Tokyo, Japan). In children less than 2 years or weighing less than $10 \mathrm{~kg}$, endoscopy was performed with a pediatric video endoscope (OLYMPUS GIF-XP190; Olympus) with a diameter of $5.8 \mathrm{~mm}$. Informed consent was obtained from the guardians of all the children. Prior to the procedure, the children fasted for at least 6 hours. Endoscopic procedures were done by 7 adult gastroenterologists with more than 10 years of experience in endoscopic practice. The procedures were done under mild sedation with midazolam $(0.05-0.1 \mathrm{mg} / \mathrm{kg} \mathrm{IV}$, maximum single dose of $4 \mathrm{mg})+$ fentanyl $(0.5-1 \mathrm{mcg} / \mathrm{kg})$ or general anesthesia with propofol $(2.5-3.5 \mathrm{mg} / \mathrm{kg}$ over 30 seconds as induction followed by $0.125-0.3 \mathrm{mg} / \mathrm{kg} / \mathrm{min}$ as maintenance) or ketamine $(1-2 \mathrm{mg} / \mathrm{kg}$ IV) supervised by an anesthetist. In some adolescents, endoscopy was done without sedation/anesthesia but under local xylocaine spray or jelly.

The indications for endoscopy in children were categorized as appropriate following the latest guidelines by ASGE and NASPGHAN published in $2014 .^{8}$ An indication was categorized as inappropriate if it was not mentioned in the guide-

Table 1. Characteristics of Study Population

\begin{tabular}{lll}
\hline Variable & $n$ & $\%$ \\
\hline Age & 278 & 33.8 \\
$\quad<12$ yr & 544 & 66.2 \\
$12-18$ yr & & \\
Sex & 436 & 53 \\
Male & 386 & 47 \\
Female & & \\
Patient status & 463 & 56.3 \\
Outpatient & 359 & 43.7 \\
Inpatient & & \\
Sedation/Anaesthesia & 250 & 30.4 \\
No sedation & 450 & 54.7 \\
Mild sedation & 122 & 14.8 \\
General anesthesia & & \\
Biopsy obtained & 210 & 25.5 \\
Yes & 612 & 74.5 \\
No & & \\
\hline
\end{tabular}


line. By analyzing the records of endoscopic procedures, the endoscopic findings were divided into positive endoscopic yield (presence of any abnormality on endoscopy) or negative endoscopic yield (no abnormality or minor abnormality). Patients with active UGI bleeding, high-grade varices, foreign body ingestion, and corrosive ingestion needed therapeutic measures to be taken during the procedure. All adverse events during or after the procedure were recorded.

Statistical analysis was done using the statistical software program (SPSS version 20.0; SPSS Inc., Chicago, IL, USA). The Chi-Square test and ANOVA were used to test for the difference between the different variables. A $p$-value of $<0.05$ was considered significant.

\section{RESULTS}

\section{Patient characteristics}

Over a period of 5 years, a total of 1,030 children underwent endoscopy. Out of this number, 822 children $(<18$ years old) met the inclusion criteria and 208 children were

Table 2. Indications of Upper Gastrointestinal Endoscopy in Children

\begin{tabular}{|c|c|c|c|}
\hline \multirow{2}{*}{ Indications } & \multirow{2}{*}{$\begin{array}{l}\text { Age } \leq 12 \text { yr } \\
\text { Count }(\%)\end{array}$} & \multirow{2}{*}{$\frac{\text { Age } 12-18 \text { yr }}{\text { Count }(\%)}$} & \multirow{2}{*}{ Total } \\
\hline & & & \\
\hline $\begin{array}{l}\text { Variceal surviellance/ } \\
\text { Eradication }\end{array}$ & $58(36.9)$ & $99(63.1)$ & 157 \\
\hline Suspected CLD & $31(33.7)$ & $61(66.3)$ & 92 \\
\hline EHPVO & $18(40)$ & $27(60)$ & 45 \\
\hline Check EGD & $9(45)$ & $11(55)$ & 20 \\
\hline Dyspepsia & $29(20.3)$ & $114(79.7)$ & 143 \\
\hline UGI bleeding & $40(29.4)$ & $96(70.6)$ & 136 \\
\hline Abdominal pain & $48(51.1)$ & $46(48.9)$ & 94 \\
\hline Anemia & $35(47.3)$ & $39(52.7)$ & 74 \\
\hline Vomiting & $20(40)$ & $30(60)$ & 50 \\
\hline GERD & $16(44.4)$ & $18(55.6)$ & 34 \\
\hline MAS & $15(53.6)$ & $13(46.4)$ & 28 \\
\hline Biliary ascariasis & $1(5.9)$ & $16(94.1)$ & 17 \\
\hline Dysphagia & $8(47.1)$ & $9(52.9)$ & 17 \\
\hline Acute pancreatitis & $2(20)$ & $8(80)$ & 10 \\
\hline Corrosive injury & $2(20)$ & $8(80)$ & 10 \\
\hline Hematochezia & $2(20)$ & $8(80)$ & 10 \\
\hline Others & $2(9.1)$ & $40(95.2)$ & 42 \\
\hline Total & $278(33.8)$ & $544(66.2)$ & 822 \\
\hline
\end{tabular}

CLD, chronic liver disease; EGD, esophagogastroduodenoscopy; EHPVO, extrahepatic portal venous obstruction; GERD, gastroesophageal reflux disease; MAS, malabsorption syndrome; UGI, upper gastrointestinal. excluded. The mean age was $13.48 \pm 4.51$ years with a minimum age of 4 months and a maximum of 18 years. Out of the 822 children, 278 (33.8\%) were younger (i.e., $<12$ years) and $544(66.2 \%)$ were older (i.e., $>12$ years); $436(53 \%)$ were males and 386 (47\%) were females. Also, 463 children (56.3\%) were from our outpatient department (OPD) and 359 were admitted to the hospital (Table 1).

\section{Indications}

The most common indications were variceal surveillance/ eradication in 157 (19.1\%) patients, which included children with suspected cirrhosis, extrahepatic portal venous obstruction, and follow-up endoscopy after endoscopic variceal ligation (EVL). The other major indications were dyspepsia in 143 (17.4\%), UGI bleeding in 136 (16.5\%), recurrent abdominal pain in 94 (11.4\%), unexplained anemia in 74 (9\%), recurrent vomiting in $50(6.08 \%)$, and chronic refractory gastroesophageal reflux disease (GERD) in 34 (4.1\%) children. Other less common indications were malabsorption syndrome

Table 3. Endoscopic Yield in Different Indications

\begin{tabular}{|c|c|c|c|c|c|}
\hline \multirow[t]{2}{*}{ Indications } & \multicolumn{2}{|c|}{$\begin{array}{c}\text { Positive } \\
\text { endoscopic } \\
\text { yield }\end{array}$} & \multicolumn{2}{|c|}{$\begin{array}{c}\text { Negative } \\
\text { endoscopic } \\
\text { yield }\end{array}$} & \multirow[t]{2}{*}{ Total } \\
\hline & $n$ & $\%$ & $n$ & $\%$ & \\
\hline \multicolumn{6}{|c|}{$\begin{array}{l}\text { Variceal surviellance/ } \\
\text { Eradication }\end{array}$} \\
\hline Suspected CLD & 32 & 34.8 & 60 & 65.2 & 92 \\
\hline EHPVO & 37 & 82.2 & 8 & 17.8 & 45 \\
\hline Check EGD & 17 & 85 & 3 & 15 & 20 \\
\hline Dyspepsia & 54 & 37.8 & 89 & 62.2 & 143 \\
\hline UGI bleeding & 97 & 71.3 & 39 & 28.7 & 136 \\
\hline Abdominal pain & 34 & 36.2 & 60 & 63.8 & 94 \\
\hline Anemia & 17 & 23.0 & 57 & 77.0 & 74 \\
\hline Vomiting & 19 & 38.0 & 31 & 62.0 & 50 \\
\hline GERD & 12 & 35.3 & 22 & 64.7 & 34 \\
\hline MAS & 6 & 21.4 & 22 & 78.6 & 28 \\
\hline Biliary ascariasis & 9 & 52.9 & 8 & 47.1 & 17 \\
\hline Dysphagia & 5 & 29.4 & 12 & 70.6 & 17 \\
\hline Acute pancreatitis & 2 & 20 & 8 & 80 & 10 \\
\hline Corrosive injury & 8 & 80.0 & 2 & 20.0 & 10 \\
\hline Hematochezia & 3 & 30.0 & 7 & 70.0 & 10 \\
\hline Others & 24 & 57.1 & 18 & 42.9 & 42 \\
\hline Total & 376 & 45.8 & 446 & 54.3 & 822 \\
\hline
\end{tabular}

CLD, chronic liver disease; EGD, esophagogastroduodenoscopy; EHPVO, extrahepatic portal venous obstruction; GERD, gastroesophageal reflux disease; MAS, malabsorption syndrome; UGI, upper gastrointestinal. 
(3.4\%), biliary ascariasis $(2.07 \%)$, dysphagia (2.07\%), corrosive ingestion, foreign body ingestion, and acute pancreatitis. The different indications and their comparison in younger and older children are shown in Table 2.

\section{Endoscopic findings and endoscopic yield}

The endoscopic yield was different for different indications (Table 3) with an overall yield of $45.8 \%$. The endoscopic yield was almost similar in younger and older children (Table 4). Out of the 143 children with dyspepsia (which included epigastric pain, postprandial fullness, epigastric discomfort, and nausea), endoscopy showed positive findings in 54 (37.8\%) patients. The endoscopic findings were duodenal ulcers in 19 , gastritis in 14, duodenitis in 8 , gastric ulcer in 2, gastric polyps in 2, trichobezoar in 1, hiatal hernia in 2 , and duodenal nodularity in one patient (Fig. 1). Out of 136 patients with UGI bleeding, 97 patients (71.3\%) had positive findings. Here, the findings were duodenal ulcers in 35 , varices in 20 , gastric ulcers in 6, esophagitis in 8, gastritis in 10, duodenitis in 4, and Mallory-Weiss tear in 4 patients. Out of 94 patients with non-specific abdominal pain, 7 patients had a duodenal ulcer, 6 were diagnosed with duodenitis, 7 with esophagitis, 5 with gastritis, 1 with gastroduodenitis, 3 with hiatal hernia, and 2 with gastric ulcero-infiltrative lesions (biopsy was suggestive of adenocarcinoma). Out of 74 patients with anemia, only 17 patients (23\%) had positive findings. Three patients had
DU, 2 had esophageal varices, 2 had ascariasis, 3 had gastritis, 1 had duodenitis, 1 had duodenal nodularity, 1 had gastro-duodenitis, 1 had esophagitis, and 1 had an esophageal stricture. Out of 50 patients with recurrent vomiting, 3 had DU, 1 had DU with Gastric Outlet Obstruction, 1 had a gastric growth (an ulcero-infiltrative lesion), 1 had a duodenal growth (i.e., a polypoid lesion), 2 had duodenitis, 4 had gastritis, 1 had gastroduodenitis, 2 had hiatal hernia, and 2 had esophagogastroduodenitis.

\section{Result of biopsies}

Biopsies were taken whenever necessary. A total of $210 \mathrm{bi}-$ opsies were taken. If the endoscopic findings were suggestive of nodular/erosive gastritis and peptic ulcer disease, a biopsy for Helicobacter pylori (to be assessed by the rapid urease test) was taken. The duodenal biopsy was done in all patients with anemia and malabsorption syndrome in whom there was no other apparent cause. The rapid urease test was positive in $85 \%$ of biopsied specimens in suspected patients. One of the patients with malabsorption syndrome and another patient with anemia had duodenal biopsy results suggestive of celiac sprue. Three patients had gastric adenocarcinoma and one patient had duodenal lymphoma.

\section{Interventional endoscopy}

Interventional endoscopy was done in 110 patients with ac-

Table 4. Comparison of Endoscopic Diagnostic Yield between Younger and Older Children

\begin{tabular}{|c|c|c|c|c|c|}
\hline \multirow{2}{*}{ Indications } & \multicolumn{2}{|c|}{ Diagnostic yield in age $\leq 12 \mathrm{yr}$} & \multicolumn{2}{|c|}{ Diagnostic yield in Age 12-18 yr } & \multirow{2}{*}{$\begin{array}{c}\text { Total } \\
n / \mathrm{N}\end{array}$} \\
\hline & $n / \mathrm{N}$ & $\%$ & $n / \mathbf{N}$ & $\%$ & \\
\hline Variceal surviellance/Eradication & $33 / 58$ & 56.9 & $55 / 99$ & 55.6 & $88 / 157$ \\
\hline Dyspepsia & $10 / 29$ & 34.5 & $44 / 114$ & 38.6 & $54 / 143$ \\
\hline UGI bleeding & $28 / 40$ & 70 & $69 / 96$ & 71.8 & $97 / 136$ \\
\hline Abdominal pain & $15 / 48$ & 31.3 & $19 / 46$ & 41.3 & $34 / 94$ \\
\hline Anemia & $9 / 35$ & 25.7 & $8 / 39$ & 20.5 & $17 / 74$ \\
\hline Vomiting & $9 / 20$ & 45 & $10 / 30$ & 33.3 & $19 / 50$ \\
\hline GERD & $5 / 16$ & 31.3 & $7 / 18$ & 38.9 & $12 / 34$ \\
\hline MAS & $3 / 15$ & 20 & $3 / 13$ & 23.1 & $6 / 28$ \\
\hline Biliary ascariasis & $0 / 1$ & - & $9 / 16$ & 56.3 & $9 / 17$ \\
\hline Dysphagia & $1 / 8$ & 12.5 & $4 / 9$ & 44.4 & $5 / 17$ \\
\hline Acute pancreatitis & $0 / 2$ & - & $2 / 8$ & 25 & $2 / 10$ \\
\hline Corrosive injury & $1 / 2$ & 50.0 & $7 / 8$ & 87.5 & $8 / 10$ \\
\hline Hematochezia & $1 / 2$ & 50.0 & $2 / 8$ & 25 & $3 / 10$ \\
\hline Others & $1 / 2$ & 50 & $21 / 40$ & 52.5 & $22 / 42$ \\
\hline Total & $116 / 278$ & 41.7 & $260 / 544$ & 47.8 & $376 / 822$ \\
\hline
\end{tabular}

$n$, number of patients with positive endoscopic findings; $N$, total number of patients.

GERD, gastroesophageal reflux disease; MAS, malabsorption syndrome; UGI, upper gastrointestinal. 
Dyspepsia
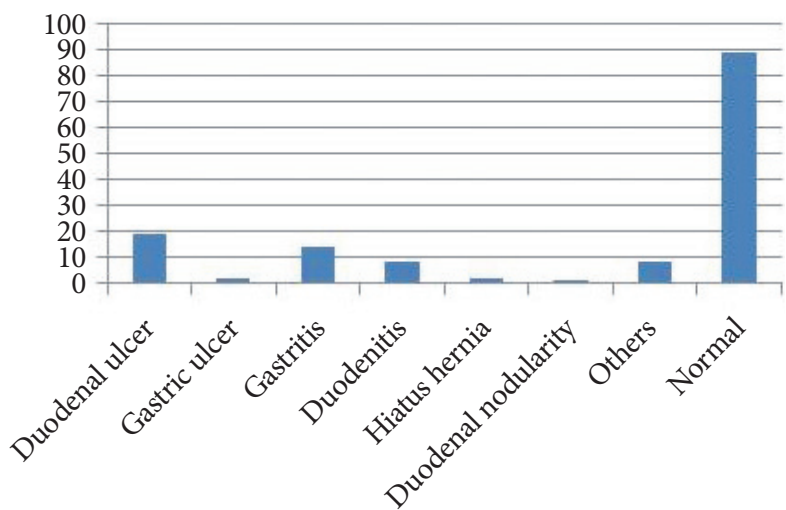

Abdominal pain

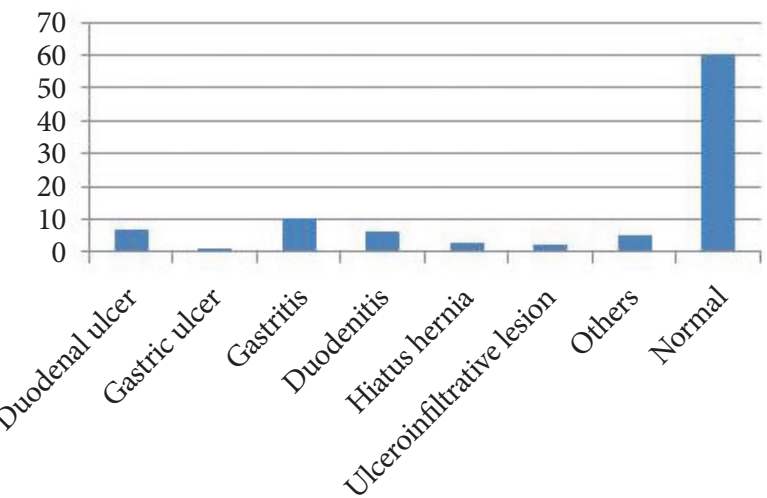

Fig. 1. Graphical representation of endoscopic findings in different indications.

tive UGI bleeding/high-grade varices, foreign body ingestion, and post-corrosive strictures and sometimes in patients with biliary ascariasis and acute pancreatitis. Ulcers with stigmata of recent hemorrhage were treated with the injection of adrenaline, heater probe coagulation, and hemoclips. Patients with high-grade varices were treated with EVL banding.

\section{Appropriateness of endoscopy}

Out of 822 endoscopic procedures in children, 780 (94.9\%) were categorized as appropriate as per the latest NASPGHAN guidelines. Forty-two endoscopic procedures (5.1\%) were considered inappropriate based on the same guidelines. Fifteen patients had non-specific abdominal pain without any significant morbidity or signs of organic disease, 10 had uncomplicated reflux, 6 had jaundice of more than 3 months duration and, in 5 patients, endoscopy was done to confirm healing of gastric or duodenal ulcers without any symptom recurrence. Further, in 6 patients, endoscopy was done prior to endoscopic retrograde cholangiopancreatography to confirm adequate passage. Ten patients with acute pancreatitis were also subjected to endoscopy which seems inappropriate based on the NASPGHAN guidelines; however, in our region, ascariasis
Upper gastrointestinal bleed
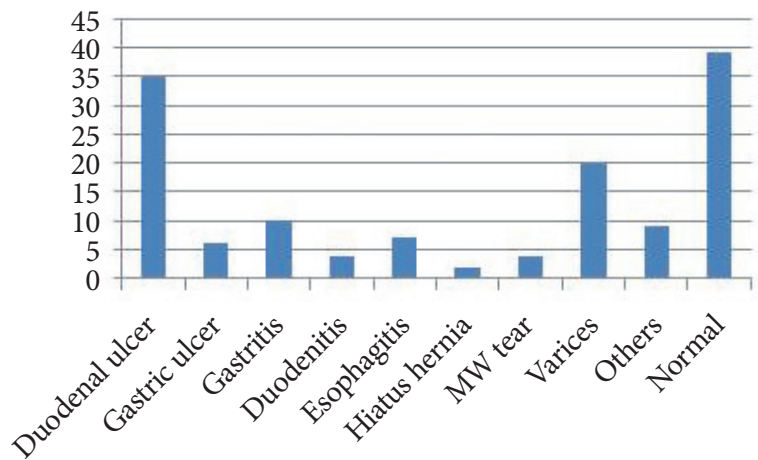

Anemia

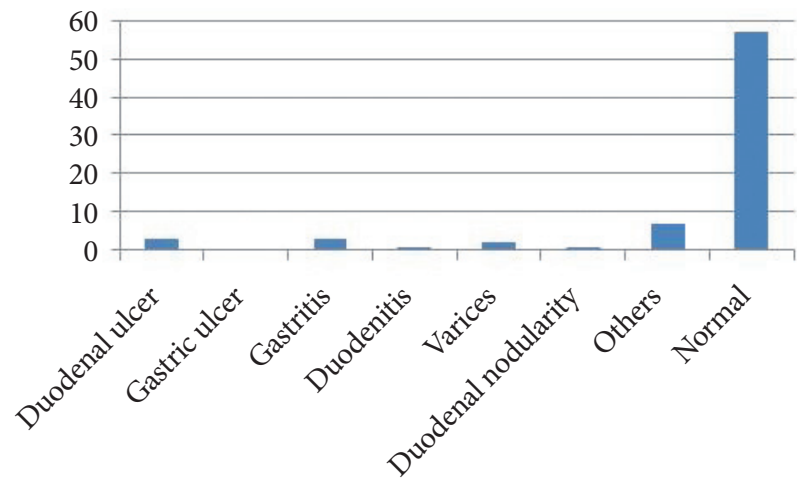

Table 5. Inappropiate Indications in Children

\begin{tabular}{lcc}
\hline Inappropriate indications & $\boldsymbol{n}$ & $\boldsymbol{\%}$ \\
\hline Non-specific abdominal pain & 15 & 35.7 \\
Uncomplicated reflux & 10 & 23.8 \\
Jaundice & 6 & 14.3 \\
Pre-ERCP & 6 & 14.3 \\
Check endoscopy for peptic ulcer healing & 5 & 11.9 \\
Total & 42 & 100 \\
\hline
\end{tabular}

ERCP, endoscopic retrograde cholangiopancreatography.

is the second leading cause of pancreatitis and endoscopy is done in cases of acute pancreatitis to look for a roundworm in and around the papillary orifice. Out of 463 OPD cases, 37 endoscopic procedures were inappropriate and out of 359 inpatient department patients, 5 endoscopic procedures were considered inappropriate ( $p=0.00002)$. We observed that inappropriate endoscopy was significantly more common in OPD patients (Table 5). 


\section{Complications}

A total of 60 adverse events were recorded (7.3\%). All of them were minor and did not affect the overall survival and hospital stay. Thirty patients complained of sore throat, 10 patients had post-extubation bronchospasm, 7 patients had fever, 7 patients complained of minor chest and abdominal pain, and 6 patients had recurrent vomiting. Thirty-five adverse events were observed in patients in whom interventional endoscopy was performed, in comparison to the 25 adverse events in the diagnostic endoscopy group $(p<0.001)$.

\section{DISCUSSION}

According to the latest endoscopic guidelines for children, pediatric endoscopy should be done by a pediatric gastroenterologist. In the absence of a pediatric gastroenterologist, it can be performed by properly trained adult gastroenterologists under the supervision of a pediatrician. However, little is known about the safety and efficacy of pediatric endoscopic procedures done by adult gastroenterologists. Our large retrospective data of 822 patients reaffirms that, in the absence of pediatric gastroenterologists, adult gastroenterologists can safely and effectively perform pediatric endoscopic procedures.

Pediatric endoscopic procedures done in our unit were appropriate in $94.9 \%$ of the cases, which is almost similar to the appropriateness in pediatric units. Ten patients with acute pancreatitis underwent endoscopy, which seemed inappropriate based on the NASPGHAN guidelines. However, in our region, ascariasis is the second leading cause of pancreatitis ${ }^{18}$ and endoscopy is often done in acute pancreatitis to look for roundworms in and around the papillary orifice. Interestingly, 2 out of 10 patients had a roundworm infection. Except in one Malaysian study where the inappropriateness was only $0.3 \%$, the remaining studies in children have shown an inappropriateness of $14.3 \%-26 \% .^{10-13}$ The reason may be that the Malaysian study was exclusively screened by gastroenterologists and the procedures were done in a pediatric unit. The other reason may be that this study was done after the ASGE/NASPGHAN guidelines got published, although one study did not find any difference before and after the publishing of these guidelines. ${ }^{11}$ We observed that inappropriate endoscopy was significantly more common in the outpatient group ( $p=0.00002$ ), which is expected as the admitted patients usually have strong indications and are thoroughly examined prior to any investigation. Similar findings have been observed in other studies. ${ }^{11}$

The indications and endoscopic findings in our study were almost similar to those of other Asian studies. The most common indications for endoscopy in children in our study were variceal surveillance/eradication in 157 (19.1\%), followed by dyspepsia in 143 (17.4\%), UGI bleeding in 136 (16.5\%), recurrent abdominal pain in 94 (11.4\%), unexplained anemia in $74(9 \%)$, recurrent vomiting in 50 (6.08\%), and refractory GERD in 34 (4.1\%). Different studies from different geographic areas have shown different indications but the overall pattern is almost similar. ${ }^{7,10,13}$ We observed positive endoscopic findings in $45.8 \%$ patients and the endoscopic yield was highest in corrosive ingestion, UGI bleeding, and variceal surveillance. Patients with anemia, malabsorption syndrome, dyspepsia, and recurrent abdominal pain had the lowest endoscopic yield. In a large retrospective study of 1,000 children from the West, the endoscopic yield was $34.7 \%$, ${ }^{14}$ whereas in another study of 231 endoscopic procedures from Malaysia, the endoscopic yield was 79\%. ${ }^{10}$ In another Western study done by adult service gastroenterologists, the endoscopic yield was $52 \%{ }^{17}$ Almost similar rates of positive endoscopic findings have been seen in most of the adult and pediatric studies. ${ }^{10,12,17,19,20}$ In a small study from Nigeria where 59 children underwent both upper and lower gastrointestinal endoscopy by adult gastroenterologists, a positive diagnostic yield of $89.8 \%$ was found without any complications. ${ }^{21}$

Adverse events were observed in only $7.3 \%$ of patients and all the adverse events were minor and did not increase morbidity or mortality. A similar safety profile has been seen in adult and other pediatric studies done in pediatric endoscopic settings. ${ }^{4,22}$

The main drawback of our study was its retrospective nature, which may have resulted in inaccurate findings especially in the underreporting of adverse events in OPD patients. Also, there were 7 different adult gastroenterologists performing the endoscopic procedures, which might have resulted in inconsistent endoscopic findings.

We conclude that in the absence of pediatric gastroenterology services, endoscopy in children can be safely and effectively performed by experienced adult gastroenterologists if done in cooperation with a pediatrician.

Conflicts of Interest

The authors have no financial conflicts of interest.

Acknowledgments

We acknowledge all the employees of our medical records section and endoscopy section.

ORCID

Showkat Ali Zargar: https:/orcid.org/0000-0002-6348-4116 Ghulam Nabi Yatoo: https://orcid.org/0000-0002-8021-672X Inaamul Haq: https://orcid.org/0000-0001-8559-8010 Altaf Shah: https://orcid.org/0000-0002-7430-7860 Jaswinder Singh Sodhi: https://orcid.org/0000-0001-9529-6518 Ghulam Mohammad Gulzar: https:/orcid.org/0000-0002-1296-8233

Mushtaq Khan: https://orcid.org/0000-0001-7766-2254 


\section{REFERENCES}

1. Freeman NV. Clinical evaluation of the fiberoptic bronchoscope (Olympus BF 5B) for pediatric endoscopy. J Pediatr Surg 1973;8:213-220.

2. Ament ME, Christie DL. Upper gastrointestinal fiberoptic endoscopy in pediatric patients. Gastroenterology 1977;72:1244-1248.

3. Gleason WA Jr, Tedesco FJ, Keating JP, Goldstein PD. Fiberoptic gastrointestinal endoscopy in infants and children. J Pediatr 1974;85:810-813.

4. Rothbaum RJ. Complications of pediatric endoscopy. Gastrointest Endosc Clin N Am 1996;6:445-459.

5. Dar AQ, Shah ZA. Anesthesia and sedation in pediatric gastrointestinal endoscopic procedures: a review. World J Gastrointest Endosc 2010;2:257-262.

6. Squires RH Jr, Colletti RB. Indications for pediatric gastrointestinal endoscopy: a medical position statement of the North American Society for Pediatric Gastroenterology and Nutrition. J Pediatr Gastroenterol Nutr 1996;23:107-110.

7. Franciosi JP, Fiorino K, Ruchelli E, et al. Changing indications for upper endoscopy in children during a 20-year period. J Pediatr Gastroenterol Nutr 2010;51:443-447.

8. ASGE Standards of Practice Committee, Lightdale JR, Acosta R, et al Modifications in endoscopic practice for pediatric patients. Gastrointest Endosc 2014;79:699-710.

9. Hassall E. Requirements for training to ensure competence of endoscopists performing invasive procedures in children. Training and Education Committee of the North American Society for Pediatric Gastroenterology and Nutrition (NASPGN), the Ad Hoc Pediatric Committee of American Society for Gastrointestinal Endoscopy (ASGE), and the executive council of NASPGN. J Pediatr Gastroenterol Nutr 1997;24:345347.

10. Lee WS, Zainuddin H, Boey CC, Chai PF. Appropriateness, endoscopic findings and contributive yield of pediatric gastrointestinal endoscopy. World J Gastroenterol 2013;19:9077-9083.

11. Jantchou P, Schirrer J, Bocquet A. Appropriateness of upper gastrointestinal endoscopy in children: a retrospective study. J Pediatr Gastroenter- ol Nutr 2007;44:440-445.

12. Miele E, Giannetti E, Martinelli M, Tramontano A, Greco L, Staiano A. Impact of the Rome II paediatric criteria on the appropriateness of the upper and lower gastrointestinal endoscopy in children. Aliment Pharmacol Ther 2010;32:582-590.

13. Guariso G, Meneghel A, Dalla Pozza LV, et al. Indications to upper gastrointestinal endoscopy in children with dyspepsia. J Pediatr Gastroenterol Nutr 2010;50:493-499.

14. Sheiko MA, Feinstein JA, Capocelli KE, Kramer RE. Diagnostic yield of EGD in children: a retrospective single-center study of 1000 cases. Gastrointest Endosc 2013;78:47-54.e1.

15. Sabir OME, Gadour MOEH. Upper gastrointestinal endoscopy in Sudanese infants and children. Sudan Journal of Medical Sciences 2007;2:9194

16. Joshi MR, Sharma SK, Baral MR. Upper GI endoscopy in children- in an adult suite. Kathmandu Univ Med J (KUMJ) 2005;3:111-114.

17. Hayat JO, Sirohi R, Gorard DA. Paediatric endoscopy performed by adult-service gastroenterologists. Eur J Gastroenterol Hepatol 2008;20:648-652

18. Khuroo MS, Rather AA, Khuroo NS, Khuroo MS. Hepatobiliary and pancreatic ascariasis. World J Gastroenterol 2016;22:7507-7517.

19. Gonvers JJ, Burnand B, Froehlich F, et al. Appropriateness and diagnostic yield of upper gastrointestinal endoscopy in an open-access endoscopy unit. Endoscopy 1996;28:661-666.

20. Seematter-Bagnoud L, Vader JP, Wietlisbach V, Froehlich F, Gonvers JJ, Burnand B. Overuse and underuse of diagnostic upper gastrointestinal endoscopy in various clinical settings. Int J Qual Health Care 1999;11:301-308.

21. Alatise OI, Anyabolu HC, Sowande O, Akinola D. Paediatric endoscopy by adult gastroenterologists in Ile-Ife, Nigeria: a viable option to increase the access to paediatric endoscopy in low resource countries. Afr J Paediatr Surg 2015;12:261-265.

22. Thakkar K, El-Serag HB, Mattek N, Gilger MA. Complications of pediatric EGD: a 4-year experience in PEDS-CORI. Gastrointest Endosc 2007;65:213-221. 